\title{
EDITORIAL
}

\section{Will oral antithrombin agents replace warfarin?}

\author{
P R Sinnaeve, F J Van de Werf
}

Heart 2004;90:827-828. doi: 10.1136/hrt.2003.030379

The new oral direct thrombin inhibitor ximelagatran is at least equivalent to warfarin for stroke prevention in patients with non-valvar atrial fibrillation, and seems to be a promising adjunct to aspirin after acute coronary syndrome

See end of article for authors' affiliations ......................

Correspondence to: F J Van de Werf, $M D, P h D$, Department of Cardiology, Gasthuisberg University Hospital Herestraat 49, B-3000 Leuven, Belgium; frans. vandewerf@uz.kuleuven. ac.be
$\mathrm{T}$ hrombosis, the result of a complex interplay between platelet activation and activation of the coagulation cascade, is a key pathophysiological mechanism in many cardiovascular disorders, including acute coronary syndromes and atrial fibrillation. Atrial fibrillation (AF) is associated with an increased risk of systemic emboli caused by intra-atrial thrombus formation, triggered by mechanical and haemostatic disturbances. In acute coronary syndromes (ACS), plaque rupture exposes von Willebrand factor and collagen, triggering platelet adhesion and activation. The coagulation cascade is also activated by complex formation of tissue factor with activated factor VII. This complex, in turn, leads to activation of factor $\mathrm{X}$ and subsequently thrombin formation.

Anticoagulation with warfarin, a vitamin K antagonist, is the mainstay of the prophylactic treatment of stroke and systemic embolic events in most patients with AF. ${ }^{1}$ An international normalised ratio (INR) of 2 to 3 is the usual target level of anticoagulation in AF. Inhibiting the coagulation cascade has also been extensively studied in ACS. The benefits of short term treatment after ACS with aspirin and heparin are well known. Nevertheless, there is evidence of a clinically relevant prothrombotic reactivation after cessation of heparin treatment, ${ }^{2}{ }^{3}$ suggesting that prolonged antithrombin treatment after ACS could be desirable. Indeed, extended administration of high intensity warfarin and moderate intensity warfarin in combination with aspirin also reduces ischaemic complications after ACS. $^{4-6}$

Until now, vitamin $\mathrm{K}$ antagonists, such as warfarin, are the only clinically available oral anticoagulants. Chronic anticoagulation, however, is often cumbersome. Not only does the effect of warfarin differ among patients, it also varies over time in the same individual. Also, various intercurrent illnesses, drugs, and food can influence the level of anticoagulation. Therefore, repeated monitoring of the anticoagulant effect and careful adjustments of warfarin dosage is necessary. In spite of these adjustments oral anticoagulation is associated with an increased risk of bleeding complications. These caveats explain in part why over $40 \%$ of patients with AF do not receive anticoagulant treatment, and why physicians are reluctant to give prolonged anticoagulant treatment after ACS.

\section{ORAL DIRECT THROMBIN INHIBITOR}

The oral direct thrombin inhibitor (DTI) ximelagatran is the first new, clinically tested, oral anticoagulant agent since warfarin was introduced more than 50 years ago. Ximelagatran is rapidly converted to its active metabolite melagatran and is mainly excreted through the kidneys. As an antithrombin, ximelagatran compares favourably with heparin or warfarin. A DTI inhibits thrombin activity better than heparin, and offers better protection against reactivation of thrombin after cessation of treatment. ${ }^{7}$ While clot bound thrombin is protected from inactivation by the heparin-antithrombin III complex, it can still be inactivated by DTI. ${ }^{8}$ Unlike warfarin, ximelagatran exerts its anticoagulant effect almost immediately, has no known drug or food interactions, and does not require frequent laboratory monitoring. Compared to low molecular weight heparin or warfarin, ximelagatran was shown to be more effective in the prevention of venous thromboembolism after surgery. ${ }^{9-11}$

Ximelagatran has been evaluated in patients with non-valvar AF with at least one high risk marker (including hypertension, age $>75$ years, previous stroke, and left ventricular dysfunction). In the SPORTIF III and V trials, ximelagatran was compared with warfarin in the prevention of stroke or systemic thromboembolic complications. In SPORTIF III, 3410 patients with AF and one or more stroke risk factors were randomised to open label, dose adjusted warfarin (target INR 2.0-3.0) or $36 \mathrm{mg}$ ximelagatran twice a day. ${ }^{12}$ Ximelagatran was shown to be equivalent to warfarin in terms of stroke prevention, and was associated with a nonsignificant $29 \%$ relative risk reduction of the primary end point of stroke or systemic embolic events. In the recently reported double blind SPORTIF V trial, the same dose of ximelagatran was tested against warfarin in 3922 patients. In the ximelagatran group, patients underwent sham INR testing and dose changes of placebo warfarin. As in SPORTIF III, ximelagatran

Abbreviations: ACS, acute coronary syndrome; $A F$, atrial fibrillation; DTI, direct thrombin inhibitor; ESTEEM, efficacy and safety of the oral direct thrombin inhibitor ximelagatran in patients with recent myocardial damage; INR, international normalised ratio; NSTEMI, non-ST elevated myocardial infarction; SPORTIF, stroke prevention using an oral thrombin inhibitor in patients with atrial fibrillation 
proved to be as effective as warfarin in the prevention of stroke and systemic embolic events.

\section{HIGH RISK ACS PATIENTS}

Ximelagatran has also been tested in high risk patients after ACS. Ximelagatran or placebo was given to 1900 patients with a recent ACS in the phase II ESTEEM trial. ${ }^{13}$ Patients were included if they had symptoms of ischaemic chest pain in the previous 14 days and at least one additional risk factor (including low ejection fraction, age above 65 years, previous myocardial infarction, congestive heart failure), a raised marker of myocardial damage, and new ischaemic electrocardiographical changes. Of these patients, $66 \%$ had an ST elevation myocardial infarction, of whom $50 \%$ had received fibrinolytic treatment. They were randomised to aspirin (160 mg) plus placebo or aspirin plus ximelagatran (24$60 \mathrm{mg}$ twice a day). Overall, ximelagatran was associated with a $24 \%$ reduction in the composite primary end point of death, myocardial infarction, and recurrent ischaemia (hazard ratio (HR) 0.76 , 95\% confidence interval (CI) 0.59 to $0.98, p=0.036$ ). No dose response was observed. In a post-hoc analysis, the "thrombotic" end point of death, nonfatal myocardial infarction, and stroke was reduced by $34 \%$ (HR $0.66,95 \%$ CI 0.48 to 0.90 ) in the total patient group allocated to the ximelagatran group. This effect was seen early on, and the Kaplan-Meier event curves tended to diverge further after 30 days, suggesting a continuing effect.

\section{SAFETY}

Is ximelagatran a perfectly safe alternative for warfarin? Unfortunately, ximelagatran induces liver enzyme elevations with serum transaminases higher than three times the upper limit within the first 2-6 months in about $6-10 \%$ of patients. ${ }^{12}{ }^{13}$ Although enzyme elevations generally seem to be benign and tend to resolve spontaneously or after drug withdrawal, monitoring of liver enzymes will probably be required during the first six months after treatment initiation. Furthermore, in the SPORTIF III and V trials, major bleeding complications were not significantly different in both treatment arms. In this respect, it is not unlikely that clinicians might also be reluctant to start ximelagatran in patients considered to be at high risk for bleeding complications with warfarin. On the other hand, the significantly lower rate of minor bleeding complications observed in the SPORTIF trials and the lack of drug or food interactions make ximelagatran a promising alternative for warfarin. Currently, regulatory approval is being sought for ximelagatran.

In the meantime, other oral antithrombin agents are being investigated in preclinical studies. ${ }^{14}$ Alternative anticoagulant strategies including oral heparin formulations ${ }^{15}$ and orally active direct anti-Xa agents ${ }^{16-18}$ are also currently being developed. Agents that inhibit activated factor $X$ are particularly promising since they block the coagulation cascade more upstream than DTI, hence also blocking thrombin generation. Although oral direct anti-Xa agents have not yet been clinically tested in patients with cardiovascular diseases, phase II trials in non-ST elevated (NSTEMI) and ST elevated myocardial infarction (STEMI) with the intravenous indirect anti-Xa agent fondaparinux have shown encouraging results. ${ }^{19} 20$

Thus, ximelagatran is at least equivalent to warfarin for stroke prevention in patients with non-valvar $\mathrm{AF}$, and seems to be a promising adjunct to aspirin after ACS. Nevertheless, more work needs to be done. Future studies need to examine the role of ximelagatran in patient categories not studied in the SPORTIF programme, including those with a lower risk for thromboembolic complications and those with valvar AF or with prosthetic heart valves. Until then, warfarin will remain firmly in the cardiologist's armamentarium. Also, the promising results of ESTEEM need to be validated in a much larger phase III trial, in other subgroups of patients with coronary artery disease-such as those with stable coronary symptoms-and in patients with dilated cardiomyopathy. Moreover, the role and safety of ximelagatran in combination with contemporary antiplatelet regimens (clopidogrel and aspirin) remains to be determined.

\section{Authors' affiliations}

P R Sinnaeve, F J Van de Werf, Department of Cardiology, University of Leuven, Leuven, Belgium

\section{REFERENCE}

1 Anon. Risk factors for stroke and efficacy of antithrombotic therapy in atria fibrillation. Analysis of pooled data from five randomized controlled trials. Arch Intern Med 1994;154:1449-57.

2 Bahit MC, Granger CB, Wallentin L. Persistence of the prothrombotic state after acute coronary syndromes: implications for treatment. Am Heart J 2002; 143:205-16.

3 Theroux $\mathbf{P}$, Waters $D$, Lam J, et al. Reactivation of unstable angina after the discontinuation of heparin. N Engl J Med 1992;327:141-5.

4 Antman EM, Cohen M, Radley D, et al. Assessment of the treatment effect of enoxaparin for unstable angina/non-Q-wave myocardial infarction. TIMI 11 B-ESSENCE meta-analysis. Circulation 1999;100:1602-8.

5 van Es RF, Jonker JJ, Verheugt FW, et al. Aspirin and coumadin after acute coronary syndromes (the ASPECT-2 study): a randomised controlled trial. Lancet 2002;360:109-13.

6 Hurlen $M$, Abdelnoor $M$, Smith $P$, et al. Warfarin, aspirin, or both after myocardial infarction. N Engl J Med 2002;347:969-74.

7 Kottke-Marchant K, Bahit MC, Granger CB, et al. Effect of hirudin vs heparin on haemostatic activity in patients with acute coronary syndromes; the GUSTO-Ilb haemostasis substudy. Eur Heart J 2002;23: 1202-12.

8 Weitz JI, Hudoba M, Massel D, et al. Clot-bound thrombin is protected from inhibition by heparin-antithrombin III but is susceptible to inactivation by antithrombin III-independent inhibitors. J Clin Invest 1990;86:385-91.

9 Francis CW, Berkowitz SD, Comp PC, et al. Comparison of ximelagatran with warfarin for the prevention of venous thromboembolism after total knee replacement. N Engl J Med 2003;349:1703-12.

10 Eriksson BI, Agnelli G, Cohen AT, et al. The direct thrombin inhibitor melagatran followed by oral ximelagatran compared with enoxaparin for the prevention of venous thromboembolism after total hip or knee replacement: the EXPRESS study. J Thromb Haemost 2003;1:2490-6.

11 Eriksson BI, Bergqvist D, Kalebo $P$, et al. Ximelagatran and melagatran compared with dalteparin for prevention of venous thromboembolism after total hip or knee replacement: the METHRO II randomised trial. Lancet 2002;360: 1441-7.

12 Olsson SB. Stroke prevention with the oral direct thrombin inhibitor ximelagatran compared with warfarin in patients with non-valvular atrial fibrillation (SPORTIF III): randomised controlled trial. Lancet 2003;362:1691-8.

13 Wallentin L, Wilcox R, Weaver WD, et al. Oral ximelagatran for secondary prophylaxis after acute myocardial infarction: the ESTEEM randomised controlled trial. Lancet 2003;362:789-97.

14 Havel $\mathrm{NH}, \mathrm{Nar} \mathrm{H}$, Priepke $\mathrm{H}$, et al. Structure-based design of novel potent nonpeptide thrombin inhibitors. J Med Chem 2002;45:1757-66.

15 Jiao Y, Ubrich N, Marchand-Arvier M, et al. In vitro and in vivo evaluation of oral heparin-loaded polymeric nanoparticles in rabbits. Circulation 2002; 105:230-5.

16 Wong PC, Pinto DJ, Knabb RM. Nonpeptide factor Xa inhibitors: DPC423, a highly potent and orally bioavailable pyrazole antithrombotic agent. Cardiovasc Drug Rev 2002;20:137-52.

17 Hirayama F, Koshio H, Katayama N, et al. The discovery of YM-60828: a potent, selective and orally-bioavailable factor Xa inhibitor. Bioorg Med Chem 2002; 10:1509-23

18 Tanabe K, Morishima Y, Shibutani T, et al. DX-9065a, an orally active factor Xa inhibitor, does not facilitate haemorrhage induced by tail transection or gastric ulcer at the effective doses in rat thrombosis model. Thromb Haemost 1999;81:828-34.

19 Coussement PK, Bassand JP, Convens C, et al. A synthetic factor-Xa inhibitor (ORG31540/SR9017A) as an adjunct to fibrinolysis in acute myocardial infarction. The PENTALYSE study. Eur Heart J 2001;22:1716-24.

20 Simoons ML, Bobbink IW, Boland J, et al. A dose finding study of fondaparinox in patients with non-ST-segment elevation acute coronary syndromes: the PENTUA study. J Am Coll Card (in press.) 